\title{
Specific Sensitization Age Dynamic in Patients with Atopic Dermatitis
}

\author{
N.G. Ilina ${ }^{*}, 1$, Yu M. Krinitsyna ${ }^{1,2}$, M. Yu. Denisov ${ }^{1}$ and I.G. Sergeeva ${ }^{1,3}$ \\ ${ }^{I}$ Novosibirsk State University (NSU) 630090 Pirogova Street 2, Novosibirsk, Russia \\ ${ }^{2}$ Institute of Regional Pathology and Pathomorphology 630117 Ak.Timakova street 2, Novosibirsk, Russia \\ ${ }^{3}$ Institute International Tomography Center of the Russian Academy of Sciences, laboratory of translational brain \\ research 630090 Institutskaia Street 3, Novosibirsk, Russia
}

\begin{abstract}
Background: Specific sensitization characterizes increased serum level of IgE to different groups of allergens (food, dust, domestic and contact). Characteristic of specific sensitization changes with age of patient. Spectrum of specific sensitization determined environmental factors, conditions of habitation.

Objective: objective was to research characteristic of specific sensitization in patients with atopic dermatitis.

Methods: There were 108 patients with atopic dermatitis, 1 st group - 31 patient (17 boys and 14 girls) 0-3y.o., 2nd group - 30 (13 boys and 17 girls) 4-13 y.o., 3rd group - 47 (16 men and 31 women) 16-63 y.o. In control group, there were 25 patients (4 men, 21 women) 16-64 y.o. with another dermatological diseases such as psoriasis, acne, rosacea and etc., without atopic dermatitis. In patients of all 4 groups evaluated personal, family allergic anamnesis, drug and food allergy, sensitization by measuring common and specific levels of immunoglobulin E.
\end{abstract}

Results: $10 \%, 32 \%, 27 \%$ patients of 1 st, 2 nd, 3rd groups had food allergy. The main allergens were citruses (37\% cases), chocolate $(27 \%)$ and milk (17\%).

Conclusion: $44-52 \%$ patients with atopic dermatitis and 4\% patients without atopy had non-specific sensitization, that characterized five-fold increased serum level of $\operatorname{IgE}$ and more.

$50-60 \%$ patients with atopic dermatitis had specific sensitization. $60 \%$ infants at the age under 3 y.o. with atopic dermatitis had sensitization for epithelium of homepets, 50\% - for milk, 30\% - white-egg. Among adults with atopic dermatitis sensitization was the same, as in control group. $35 \%$ patients with dermatoses without atopy had specific sensitization.

Keywords: Atopic dermatitis, food allergy, immunoglobulin E, sensitization.

\section{INTRODUCTION}

There are currently two major pathogenetic forms of atopic dermatitis: truly allergic or allergic and atopiform or non-allergic. The allergic (extrinsic) form is associated with hypersensitivity to food and/or other allergens as well as increased levels of $\operatorname{IgE}$ in patients and is observed in 70 $80 \%$ of patients. The non-allergic (intrinsic) form is characterised by normal levels of IgE and is observed in 20 $30 \%$ of patients $[1,2]$.

Specific hypersensitivity is characterised by increased levels of immunoglobulin $\mathrm{E}$ to various allergen groups (food, dust, household, and contact) [3]. Changes in the nature of food, dust, and household hypersensitivity are observed with age. The range of specific hypersensitivity is associated with environmental factors, living conditions, and everyday life. Thus, it has been shown that visiting a swimming pool with chlorinated water before the age of 3 increases the risk of specific hypersensitivity to house dust mites [4].

*Address correspondence to this author at the Novosibirsk State University (NSU) 630090 Pirogova Street 2, Novosibirsk, Russia;

Tel: +4915202837021; E-mail: dr.natalia.ilina@gmail.com
With the introduction of laboratory methods such as the measurement of the level of total immunoglobulin $\mathrm{E}$ and levels of specific immunoglobulin $\mathrm{E}$ in practice, the progression of the disease may be assessed, and case management tactics may be determined [5-7].

The purpose of the study was to determine the nature of specific hypersensitivity in patients with atopic dermatitis in relation to ageing.

\section{MATERIALS AND METHODS}

We observed 108 patients with atopic dermatitis aged 0 to 63 years. Depending on the age, the patients were divided into the following groups: Group $1-31$ persons (17 boys, 14 girls) aged 0 to 3 , Group $2-30$ patients (13 boys and 17 girls) aged 4 to 13 , and Group $3-47$ patients (16 men and 31 women) aged 16 to 63 . In all cases, the diagnosis of atopic dermatitis was made by a dermatologist; at the time of referral, all patients had clinical manifestations that met atopic dermatitis criteria. All patients were treated on an outpatient basis, depending on the nature and severity of the disease. To form a control group by the random sampling method, 25 patients with other skin diseases (acne, rosacea, 
psoriasis, contact dermatitis, allergic contact dermatitis), without having been diagnosed with atopic dermatitis at the time of examination or in the medical history, (4 men and 21 women) aged 16 to 64 were selected.

All patients were assessed for personal and family allergic history and for clinical manifestations of allergy to different groups of allergens (food, drugs, dust, and contact).

The prevalence of hypersensitivity was evaluated by the level of total immunoglobulin $\mathrm{IgE}$ according to age-based normal ranges.

To determine the nature of specific hypersensitivity, the standardised kit was used for immunoblot RIDA ${ }^{\circledR}$ Allergy Screen A2442 Panel No. 4 (paediatric), comprising 20 major allergens: food - cow's milk allergens ( $\alpha$-lactalbumin, $\beta$ lactalbumin, casein, and bovine serum albumin), and allergens of egg whites and yolks, soy, carrots, potatoes, wheat flour, hazelnuts, and peanuts; house dust mites Dermatophagoides pteronyssinus and Dermatophagoides farinae; household allergens - cat and dog hair; fungal allergens - Alternaria alternata; and pollen allergens - birch and various grasses. Increased specific immunoglobulin IgE at a level above the threshold - i.e. over $0.35 \mathrm{IU} / \mathrm{ml}$ - was considered a criterion of positive specific hypersensitivity.

Statistical data were processed using the Student's t-test for qualitative parameters.

All patients gave signed informed consent for data examination and processing.

\section{RESULTS}

Based on the personal allergic history of patients with atopic dermatitis, an increasing incidence of bronchial asthma with age from $3.3 \%$ in infants to $10.6 \%$ in older patients and of allergic rhinitis from $3.2 \%$ in children to $14.9 \%$ in adults was observed (Table 1). There were no cases of bronchial asthma or allergic rhinitis in the control group patients.

The family history of allergenic diseases was considered burdened if the patient stated cases of bronchial asthma, allergic rhinitis, Quincke's oedema, urticaria, or allergic reactions to foods and drugs in relatives of first and second lines of kinship. The family history of allergenic diseases was burdened in $43.3 \%, 38.7 \%, 36.2 \%$, and $20.0 \%(p<0.05)$ of cases of patients from Groups 1, 2, 3, and 4 (Table 1).

Among all cases of food allergies, the most common causes were citrus in $36.7 \%$ of cases, chocolate in $26.7 \%$, and milk in $16.7 \%$. According to parents, the group 1 patients were allergic to milk formula, vegetable solid foods, citrus fruits, and carrots; and group 2 patients to milk formula and in a few cases to tomatoes, kiwi, and fish. In individual cases, group 3 patients mentioned reactions to milk, grapes, strawberries, sea buckthorn, peaches, kiwi, cherries, watermelon, tomatoes, food additives, and honey. The control group patients had allergic reactions to CocaCola and chicken eggs.

Group 3 patients often indicated drug hypersensitivity compared with patients from groups 1 and $2 \quad(p<0.005)$ (Table 1). Among all allergic reactions to drugs, $20 \%$ of patients reported hypersensitivity to penicillin drugs. Moreover, group 1 patients had reactions when using drugs containing nifuroxazide, bacteriophage, and ibuprofen; and group 3 patients when using drugs containing azithromycin, fluoroquinolones, hexetidine, glycine, nicotinic acid, and phytopreparations. The control group patients had allergies to gentamicin and diphenhydramine.

The allergic history data obtained for patients are subjective, as reported by the patients or their parents. For an objective assessment of the allergic status of a patient, the levels of total and specific immunoglobulin $\mathrm{E}$ were utilised.

Increased total immunoglobulin in patients with atopic dermatitis was observed in $55.5 \%, 64.3 \%$, and $52.4 \%$ of cases in groups 1,2 , and 3 significantly more often than in the control group of patients $-17.3 \%(p<0.01)$.

Total immunoglobulin $\operatorname{IgE}$ in patients with atopic dermatitis was consistent with normal age ranges in about half of the cases in patients of group 1 and about a third of the cases in patients of the groups 2 and 3. In the control group, $82.7 \%$ of patients had total immunoglobulin consistent with normal ranges (Table 2). In half of the cases in patients with atopic dermatitis, 5 times or higher $\operatorname{IgE}$

Table 1. Clinical parameters of the allergic status in observed patients $\%$.

\begin{tabular}{|c|c|c|c|c|}
\hline & $\underset{n=31}{\text { Group } 1}$ & $\underset{n=30}{\text { Group }} 2$ & $\underset{n=47}{\text { Group }} 3$ & $\underset{n=25}{\text { Group }} 4$ \\
\hline \multicolumn{5}{|l|}{ Personal history of allergies } \\
\hline Bronchial asthma & 3.3 & 6.5 & 10.6 & - \\
\hline Allergic rhinitis & - & 3.2 & 14.9 & - \\
\hline Food allergy & 10.0 & 32.3 & 27.7 & 16.0 \\
\hline Drug hypersensitivity & 6.6 & 3.2 & 25.5 & 20.0 \\
\hline \multicolumn{5}{|l|}{ Family history of allergies } \\
\hline Atopic dermatitis in family members & 26.7 & 19.4 & 14.9 & - \\
\hline
\end{tabular}


levels were observed in $44.4 \%, 50.0 \%$, and $52.4 \%$, which was significantly higher than in the control group $-4.3 \%$ $(\mathrm{p}<0.01)$. A moderate increase in total immunoglobulin up to 5 times was observed in isolated cases $-11.1 \%, 14.3 \%$, $9.5 \%$, and $13.0 \%$ of patients of Groups $1,2,3$, and 4 .

Increased levels of $\mathrm{IgE}$ antibodies were observed in
$60.0 \%, 57.1 \%, 50.0 \%$, and $35.3 \%$ of patients of Groups 1,2 , and 3 as well as the control group. Only $4.5 \%$ of the patients with atopic dermatitis, who had a significant increase in total immunoglobulin $(429 \mathrm{IU} / \mathrm{ml})$, demonstrated no increase in specific immunoglobulins.

In patients of group 1, most significant were an increase

Table 2. Nature of the increase of total immunoglobulin IgE in observed patients, $\%$

\begin{tabular}{|c|c|c|c|}
\hline Group & Normal Range & Increase up to 5 Times & Increase up to 5 Times and Higher \\
\hline \hline $\begin{array}{c}\text { Group 1 } \\
\mathrm{n}=31\end{array}$ & 44.4 & 11.1 & 44.4 \\
\hline $\begin{array}{c}\text { Group 2 } \\
\mathrm{n}=30\end{array}$ & 35.7 & 14.3 & 50.0 \\
\hline $\begin{array}{c}\text { Group 3 } \\
\mathrm{n}=47\end{array}$ & 38.1 & 9.5 & 52.4 \\
\hline $\begin{array}{c}\text { Group 4 } \\
\mathrm{n}=25\end{array}$ & $82.7^{*}$ & 13.0 & $4.3^{*}$ \\
\hline
\end{tabular}

Table 3. Detection rate of specific hypersensitivity in observed patients, $\%$

\begin{tabular}{|c|c|c|c|c|}
\hline Allergen & $\begin{array}{c}\text { Group } 1 \\
\mathbf{n}=\mathbf{3 1}\end{array}$ & $\begin{array}{c}\text { Group } 2 \\
\mathbf{n}=\mathbf{3 0}\end{array}$ & $\begin{array}{c}\text { Group } 3 \\
\mathbf{n}=47\end{array}$ & $\begin{array}{c}\text { Group } \\
n=25\end{array}$ \\
\hline \multicolumn{5}{|l|}{ Aeroallergens } \\
\hline House dust mites & - & 7.1 & 16.6 & 23.6 \\
\hline Birch - pollen & 10.0 & 7.1 & 5.6 & 5.9 \\
\hline Various grasses - pollen & - & - & 11.1 & 11.8 \\
\hline Fungus Alternaria alternata & - & 7.1 & 11.1 & 11.8 \\
\hline \multicolumn{5}{|l|}{ Household allergens } \\
\hline Epithelium and animal hair (cat, dog) & 60.0 & 14.2 & 27.8 & 5.9 \\
\hline \multicolumn{5}{|l|}{ Food allergens } \\
\hline \multicolumn{5}{|l|}{ Milk and dairy products } \\
\hline Milk & 50.0 & 35.7 & 11.1 & 11.8 \\
\hline A-lactoglobulin & 10.0 & 35.7 & 11.1 & 5.9 \\
\hline B-lactoglobulin & 30.0 & 7.1 & - & - \\
\hline Casein & 30.0 & 28.6 & 16.7 & 11.8 \\
\hline Egg white & 30.0 & - & 5.6 & 11.8 \\
\hline Egg yolk & - & - & - & 5.9 \\
\hline Bovine serum albumin & 10.0 & - & - & - \\
\hline \multicolumn{5}{|l|}{ Vegetables } \\
\hline Carrots & 20.0 & - & - & 5.9 \\
\hline Potatoes & 10.0 & - & - & 5.9 \\
\hline Soybeans & - & - & - & - \\
\hline \multicolumn{5}{|l|}{ Nuts and cereals } \\
\hline Wheat flour & 20.0 & 7.1 & 5.6 & 11.8 \\
\hline Hazelnuts & 20.0 & - & - & 11.8 \\
\hline Peanuts & 10.0 & - & - & - \\
\hline
\end{tabular}


of levels to epithelium and animal hair $-60.0 \%$, to milk $50.0 \%$, and to lactoglobulin, casein, and egg whites $-30.0 \%$. In patients of group 2, 37.5\% had elevated levels of E-class antibodies, specific for alpha-lactoglobulin and milk, and $28.6 \%$ of the cases for casein. In the patients of group 3, $27.8 \%$ of the cases manifested higher frequency of detected immunoglobulin $\mathrm{E}$ to hair and dog epithelium, and $16.7 \%$ of the cases to casein. In patients in Group 3, $11.1 \%$ of the cases showed specific hypersensitivity to milk, which is consistent with this parameter in the control group. Hypersensitivity to the remaining dust and food allergens in older patients was observed in isolated cases. In patients of the control group, elevated specific immunoglobulins were observed in a few cases; no predominant allergens were identified (Table 3).

In group 3, the frequency of specific hypersensitivity to foods did not differ from those obtained in the control group.

\section{DISCUSSION}

The prevalence of food allergies in patients with atopic dermatitis is from $35 \%$ to $90 \%$ according to the data of various authors, in patients with a children's form $-8.3 \%$ [810]. According to our data, $10.0 \%, 32.3 \%$, and $27.7 \%$ of infants, children, and older patients had a food allergy.

It is important to bear in mind that, in all patients with atopic dermatitis with symptoms of food allergy, only 30 $40 \%$ have specific hypersensitivity verified by enzyme immunoassay or food provocation in a double-blind, placebo-controlled study [11]. Food allergens indicated by patients are subjective. In most cases, the enzyme immunoassay revealed no specific hypersensitivity to the allergens indicated by the patients. Moreover, the allergens identified by the laboratory method point to existing hidden hypersensitivity.

The most common cause of food allergies in patients with atopic dermatitis is milk and dairy products. Cow's milk is the most allergenic food. Higher milk fat and increased protein content enhance its allergenic properties.

According to various sources, the frequency of hypersensitivity is from $8.4 \%$ to $41.2 \%[12,13]$. In infants and children with atopic dermatitis, hypersensitivity to milk was observed in $50.0 \%$ and $35.7 \%$ of the cases. Unchanged hypersensitivity to milk in adults was observed in $11.1 \%$, but these results were comparable in frequency with the control group patients $-11.8 \%$. Based on the results of other studies, hypersensitivity to cow's milk proteins and casein in infants with severe atopic dermatitis is up to $92.3 \%$ [10].

However, protein fractions have the most allergenic properties. Cow's milk contains from 2.8 to $4.1 \mathrm{~g}$ of protein per $100 \mathrm{ml}$. Beta-lactoglobulin of cow's milk is considered the most allergenic, especially for children, as it is absent in human milk [14]. The incidence of allergic reactions to betalactoglobulin is $60-70 \%$. Based on our data, hypersensitivity to beta-lactoglobulin was observed in $30.0 \%$ of infants, less frequently than in children $-7.1 \%$. In paediatric patients, hypersensitivity to alpha-lactoglobulin was observed more frequently $-35.7 \%$.
Based on the results of our study, $60.0 \%$ of infants with atopic dermatitis had hypersensitivity to epithelium and cat and dog hair. The need for maintenance of hypoallergenic living conditions has been discussed. Thus, the impact of prenatal exposure of the mother to farm animals significantly reduces the risk of atopic dermatitis in children by half [15]. According to EU guidelines, the exposure to aeroallergens should be minimal [16]. Hypersensitivity to epithelium and animal hair in the control group was lower (5.9\%) compared with older patients with atopic dermatitis $(27.8 \%)(p<0.01)$.

Hypersensitivity to egg and aeroallergens detected at an early age in children with atopic dermatitis is a compelling risk factor for bronchial asthma. In case of an allergy to egg protein, both intolerance to chicken meat and increased sensitivity to pillow feathers are sometimes identified. According to studies, the frequency of hypersensitivity to eggs is $32 \%$ [13]. Vetellin protein contained in egg yolk is characterised by less pronounced allergenic properties. Sometimes there is selective protein or egg yolk intolerance. According to our data, $30.0 \%$ of infants had hypersensitivity to chicken protein. Hypersensitivity to egg yolks was not identified in any cases in patients with atopic dermatitis, and only in $5.9 \%$ of control group patients.

Hypersensitivity to aeroallergens is more typical for patients with adolescent and adult forms of atopic dermatitis 16. According to the literature, the most common aeroallergen in patients with atopic dermatitis aged 3 to 6 is house the dust mite Derm. farinae [17]. According to the obtained data, hypersensitivity to house dust mites was observed more frequently in patients with children's and adult forms $-7.10 \%$ and $16.6 \%$, respectively; hypersensitivity to birch pollen was observed in $10.0 \%, 7.1 \%$, and $5.6 \%$ of cases in patients of all three groups.

Among foods, the significant allergens were carrots, potatoes, wheat, and certain products introduced as supplementary food for infants.

$30.0 \%$ of infants with atopic dermatitis demonstrated hypersensitivity to nuts - hazelnuts and peanuts. Nuts are not a staple product among children or an introduced supplementary product; however, nuts may be added to foods as flavourings or additives.

The distribution of allergic and non-allergic forms of atopic dermatitis by total immunoglobulin was consistent with the data obtained in other studies 1 . In $44.4 \%, 35.73 \%$, and $38.1 \%$ of the cases, total immunoglobulin was within the normal age-based range, which was consistent with the nonallergic form of atopic dermatitis. A pronounced increase in the level of total immunoglobulin (5 times or higher) was observed in $44.4 \%, 50.0 \%$, and $52.4 \%$ of patients with atopic dermatitis, significantly less than in control group patients.

Thus, specific hypersensitivity in atopic dermatitis varies with age and in patients older than 16 did not differ from hypersensitivity in patients with non-allergic dermatoses.

\section{CONFLICT OF INTEREST}

The authors confirm that this article content has no conflict of interest. 


\section{ACKNOWLEDGEMENTS}

This work was financially supported by the Russian Science Foundation (project \# 14-35-00020).

\section{REFERENCES}

[1] Suárez-Fariñas M, Dhingra N, Gittler J, et al. Intrinsic atopic dermatitis shows similar TH2 and higher TH17 immune activation compared with extrinsic atopic dermatitis. J Allergy Clin Immunol 2013; 132(2): 361-70.

[2] Liu FT, Goodarzi H, Chen HY. IgE, mast cells, and eosinophils in atopic dermatitis. Clin Rev Allergy Immunol 2011; 41(3): 298-310.

[3] Zheng T, Yu J, Oh MH, Zhu Z. The atopic march: progression from atopic dermatitis to allergic rhinitis and asthma (review). Allergy Asthma Immunol Res 2011; 3(2): 67-73.

[4] Voisin C, Sardella A, Bernard A. Risks of new-onset allergic sensitization and airway inflammation after early age swimming in chlorinated pools. Int J Hyg Environ Health 2014; 217(1): 38-45.

[5] Manam S, Tsakok T, Till S, Flohr C. The association between atopic dermatitis and food allergy in adults. Curr Opin Allergy Clin Immunol 2014; 14(5): 423-9.

[6] Gray CL, Levin ME, Zar HJ, et al. Food allergy in South African children with atopic dermatitis. Pediatr Allergy Immunol 2015 [Epub ahead of print].

[7] Just J, Deslandes-Boutmy E, Amat F, et al. Natural history of allergic sensitization in infants with early-onset atopic dermatitis: results from ORCA Study. Pediatr Allergy Immunol (E-pub at 2014 Oct 6).
[8] Lee CH, Kim HO, Cho SI, et al. Food Hy-persensitivity in patients with childhood atopic dermatitis in Korea. Ann Dermatol 2013; 25(2): 196-202.

[9] Kwon J, Kim J, Cho S, Noh G, Lee SS. Characterization of food allergies in patients with atopic dermatitis. Nutr Res Pract 2013; 7(2): $115-21$.

[10] Sicherer SH, Sampson HA. Food allergy: epidemiology, pathogenesis, diag-nosis, and treatment. J Allergy Clin Immunol 2014; 133(2): 291-307.

[11] Campbell DE. Role of food allergy in childhood atopic dermatitis. J Paediatr Child Health 2012; 48: 1058-64.

[12] Bergmann MM, Caubet JC, Boguniewicz M, Eigenmann PA. Evaluation of food allergy in patients with atopic dermatitis. J Allergy Clin Immunol Pract 2013; 1(1): 22-28.

[13] Forsey RG. Prevalence of childhood eczema and food sensitization in the First Nations reserve of Natuashish, Labrador, Canada. BMC Pediatr 2014; 14: 76.

[14] Duan CC, Li AL, Yang LJ, Zhao R, Fan WG, Huo GC Comparison of immunomodulating properties of Beta-lactoglobulin and its hydrolysates. Iran J Allergy Asthma Immunol 2014; 13(1): 26-32.

[15] Roduit C, Wohlgensinger J, Frei R. Prenatal animal contact and gene expres-sion of innate immunity receptors at birth are associated with atopic dermatitis. J Allergy Clin Immunol 2011; 127(1): 179-85.

[16] Schneider L, Tilles S. Atopic dermatitis: a practice parameter update 2012. J Allergy Clin Immunol 2013: 295-9.

[17] Kim EJ, Kwon JW, Lim YM, et al. As-sessment of total/specific IgE levels against 7 inhalant allergens in children aged 3 to 6 years in Seoul, Korea. Allergy Asthma Immunol Res 2013; 5(3): 162-9.

(C) Ilina et al.; Licensee Bentham Open.

This is an open access article licensed under the terms of the Creative Commons Attribution Non-Commercial License (http://creativecommons.org/licenses/by-nc/ 4.0/) which permits unrestricted, non-commercial use, distribution and reproduction in any medium, provided the work is properly cited. 